\title{
Efeito da embalagem e da irradiação gama no controle da contaminação microbiana da manga minimamente processada
}

\section{Effect of the packing and the gama irradiation on the microbiological contamination control of the minimally processed mango}

\author{
Rogério Lopes Vieites ${ }^{1 *}$; Regina Marta Evangelista ${ }^{1}$; \\ André José de Campos ${ }^{2}$; Glaucia Cristina Moreira ${ }^{2}$
}

\section{Resumo}

O objetivo do presente trabalho foi avaliar a contaminação microbiana da manga Tommy Atkins. Os frutos foram lavados em água, descascados, cortados manualmente em cubos de $3 \times 3 \mathrm{~cm}$ e acondicionados em embalagens tipo PET, copos plásticos transparentes $(250 \mathrm{ml})$ e saco plástico $(25 \mathrm{~mm})$ a vácuo. A seguir foram irradiados nas doses 0,$0 ; 0,1 ; 0,2 ; 0,3 ; 0,4$ e $0,5 \mathrm{kGy}$ ), e armazenados a $5^{\circ} \mathrm{C}$ com $85 \%$ de umidade relativa. A cada dois dias foram avaliados a incidência de coliformes, microrganismos mesófilos e psicotróficos. Pelos resultados obtidos pôde-se verificar após 10 dias de armazenamento, que os frutos com as doses de 0,4 e 0,5 kGy, armazenados em embalagem tipo PET e copo plástico, apresentaram menores quantidades de mesófilos e psicotróficos, enquanto os frutos da testemunha apresentaram uma grande quantidade de mesófilos e psicotróficos, sendo considerados impróprios para o consumo após o quarto dia de armazenamento. Pode-se concluir que a irradiação nas doses de 0,4 e 0,5 kGy nas diferentes embalagens foram efetivas no tratamento da manga minimamente processada.

Palavras-chave: Radiação, processamento mínimo, qualidade, manga.

\begin{abstract}
The objective of this work was to verify the microbiological contamination of mangoes Tommy Atkins minimally processed and irradiated. The fruits were washed in water, peeled, manually cut in cubes of 3 $\mathrm{x} 3 \mathrm{~cm}$ and conditioned in packages of polyethylene terphthalate (PET) tray Neoform, transparent plastic glass with cover $(250 \mathrm{ml})$, and plastic bag $(25 \mathrm{~mm})$ under vaccum. After that, they were in the EMBRARAD company, with the doses T1 (control), T2 (0,1 kGy), T3 (0,2 kGy), T4 (0,3 kGy), T5 (0,4 kGy) and T6 (0,5 $\mathrm{kGy}$ ), and stored under $5^{\circ} \mathrm{C}$ and $85 \% \mathrm{RM}$. Every 2 days of storage, the fruits were evaluated for the incidence of coliforms, mesophiles and psychrophiles microorganisms. From the obtained results is it verified at the end of a 10-day period, the fruits with 0,4 and $0,5 \mathrm{kGy}$ doses and packages of polyethylene terphthalate (PET) tray Neoform, transparent plastic glass with cover $(250 \mathrm{ml})$, presented the smallest mesophile and psychrophile rates, while the fruits control presented the largest mesophile and psychrophile rates, being considered inappropriate for consuption from the fifith day of storage. Terefore it can be concluded that the radiation with 0,4 and $0,5 \mathrm{kGy}$ doses was an effective treatment in the minimally processed mangoes.
\end{abstract}

Key words: Radiation, fresh cut, quality, mangoes.

1 Professor Adjunto, Universidade Estadual Paulista (UNESP), Campus de Botucatu, Faculdade de Ciências Agronômicas, Departamento de Gestão e Tecnologia Agroindustrial, Botucatu, SP. E-mail vieites@fca.unesp.br.

2 Aluno de Pós-Graduação da Universidade Estadual Paulista (UNESP), Campus de Botucatu, Faculdade de Ciências Agronômicas, Departamento de Gestão e Tecnologia Agroindustrial, Caixa Postal 237, CEP 18603-970 Botucatu.

* Autor para correspondência. 


\section{Introdução}

Nos últimos anos, tem-se enfatizado a necessidade do consumo de frutas e hortaliças frescas, buscando-se uma dieta saudável, ao mesmo tempo em que há uma demanda crescente de alimentos mais convenientes, frescos, que sejam menos processados e prontos para o consumo. A indústria de alimentos tem respondido a essa demanda, com o desenvolvimento de técnicas de conservação caracterizadas por um processamento mínimo do produto (VANETTI, 2000).

O preço dos produtos minimamente processados são, em média, cerca de $180 \%$ superior ao das mesmas frutas comercializadas a granel (SAABOR, 1999).

Enquanto a maioria das técnicas de processamento de alimentos estabilizam os produtos, estendendo sua vida de prateleira, o processamento mínimo de frutos e hortaliças aumenta sua perecibilidade (SHEWFELT, 1986). Por isso, além de maior controle da sanitização, é recomendável que outras técnicas sejam utilizadas adicionalmente para que o período de conservação do produto seja estendido (WATADA; ABE; YAMUCHE, 1990; WILEY, 1997).

O`Connor-Shaw et al. (1994) obtiveram uma vida de prateleira de 04 dias para mamão minimamente processados embalados em caixas de polipropileno a temperatura de $4^{\circ} \mathrm{C}$. As causas das perdas observadas foram a descoloração e o amaciamento dos pedaços do fruto. $\mathrm{O}$ crescimento microbiano não contribuiu para a deterioração da aparência do produto neste período.

Jerônimo e Kanesiro (2000) avaliaram o efeito do armazenamento refrigerado associado à atmosfera modificada através do uso de embalagem, na qualidade e na vida útil de mangas "Palmer”. O armazenamento refrigerado retardou $o$ amadurecimento dos frutos, o uso das embalagens diminuiu a perda de massa, principalmente nos frutos armazenados sob refrigeração, mas não interferiu na evolução dos teores de acidez total titulável sólidos solúveis totais e vitamina $\mathrm{C}$.
Segundo Ahvenainen (1996) durante o descascamento, corte e fatiamento, a superfície do produto vegetal é exposta ao ar e, com isso é possível a contaminação com bactérias, leveduras e mofos. A microbiota de frutas e hortaliças frescas consiste, em geral, de espécies de Enterobactérias e Pseudomonas, enquanto bactérias do ácido lático e fungos podem estar presentes em números relativamente baixos (NGUYEN-THE; CARLIN, 1994). Ocasionalmente, patógenos podem ocorrer em razão do uso de água para irrigação ou fertilizantes contaminados, durante o cultivo, ou como uma consequência da falta de higiêne durante o processamento. Porém o crescimento de microrganismos patogênicos e deterioradores em produtos minimamente processados pode ser inibido ou retardado pela combinação adequada de atmosfera modifica e temperatura.

Dentre os patógenos psicotróficos encontrados em hortaliças minimamente processadas mantidos sob refrigeração destacam-se L. monocytogenes, Yersinia enterocolitica e Aeromonas hydrophyla. Entretanto outros microrganismos patogênicos são de relevância nesses produtos e incluem a Salmonella, Shigella, Campylobacter, Escherichia coli, Staphylococcus aureus, C. botulinium, Bacillus cereus, espécies de Vibrio, vírus da hepatite A e Norwalk, além de parasitas como Cryptosporidium e Cyclospora (CHERRY, 1999).

Em revisão sobre a microbiologia de frutas e hortaliças minimamente processadas, Nguyen-The e Carlin (1994) relataram que a contagem de bactérias mesófilas em agar padrão ou meio equivalente, encontrada por vários autores,variou de $10^{3}$ a $10^{9}$ $\mathrm{UFCg}^{-1}$, dependendo do local de amostragem e do tempo decorrido até a análise. As contagens de bactérias lácticas, sob condições de anaerobiose, alcançaram $10^{9} \mathrm{UFCg}^{-1}$, em alguns casos. Coliformes em meio seletivo representaram uma pequena porção dos contaminantes bacterianos, enquanto os coliformes fecais não foram detectados na maioria das amostras estudadas. As leveduras e fungos filamentosos foram, em geral, menos numerosos que as bactérias mesófilas ou lácticas. 
A resolução $\mathrm{n}^{\circ} 12$ de 02 de janeiro de 2002 da Agência Nacional de Vigilância Sanitária do Ministério da Saúde estabelece como padrão, o máximo de $5 \times 10^{2}$ NMP de coliformes fecais por grama de fruta in natura ou minimamente processadas. Embora não existam na legislação padrões para bactérias mesófilas totais e coliformes totais, de forma geral, é preconizado que alimentos contendo contagens microbianas da ordem de $10^{5}$ $10^{6} \mathrm{UFCg}^{-1}$ são impróprios para o consumo humano devido a perda do valor nutricional, alterações organolépticas, riscos de deterioração e/ou presença de patógenos (AGÊNCIA NACIONAL DE VIGILÂNCIA SANITÁRIA, 2002).

Atenção especial deve ser dada em relação à contaminação microbiologica de frutos e hortaliças minimamente processados, uma vez que, sob condições de baixo pH e temperaturas de refrigeração, os fungos podem crescer e se tornarem predominantes. Certos fungos filamentosos produzem micotoxinas em alimentos que, quando ingeridos, causam sintomas tóxicos, tanto no homem como nos animais. Várias micotoxinas têm sido associadas à ação carcinogênica e mutagênica. Os gêneros de fungos de maior importância para humanos, com respeito a surtos de intoxicação, são: Aspergillus, Penicillium e Fusarium ssp (CARVALHO, 2000).

Segundo Odumero et al. (1997) os produtos minimamente processados devem ser mantidos a $4+/-1^{\circ} \mathrm{C}$, durante o processamento, o transporte e o armazenamento até o consumo. Temperaturas mais baixas, como $0^{\circ} \mathrm{C}$, durante o processamento podem causar injúrias no tecido das frutas e hortaliças minimamente processadas (BRECHT, 1995).

A compreensão dos efeitos que os principais gases presentes em embalagens sob atmosfera modificada exercem sobre a microbiota do produto é fundamental para prever o comportamento dessa microbota e, dessa forma, estimar o tempo de conservação do produto. $\mathrm{O}$ oxigênio, em geral, permite o crescimento de bactérias aeróbias e pode inibir o crescimento dos anaeróbios estritos, embora exista uma grande variação na sensibilidade dos aeróbios ao $\mathrm{O}_{2}$. A redução do oxigênio no interior da embalagem, inibe a proliferação da microbiota aeróbia presente mas vai estimular o crescimento de microaerófilos e anaeróbios.

O gás carbônico, solúvel em água e lipídeos, é o principal responsável pelo efeito bacteriostático observado em microrganismos nos produtos minimamente processados embalados sob atmosfera modificada (LANA; FINGER, 2000). Segundo os mesmos autores existem diversas teorias sobre o modo de ação do $\mathrm{CO}_{2}$ sobre as bactérias, que podem ser assim resumidas: alterações das funções da membrana microbiana; inibição direta ou decréscimo da velocidade de reações enzimáticas; penetração na membrana celular e consequente alteração no $\mathrm{pH}$ intracelular e alterações nas propriedades físicoquímicas das proteínas. O efeito combinado das interações metabólicas causadas pelo $\mathrm{CO}_{2}$ estressam a célula e resultam em decréscimo na velocidade da taxa de crescimento microbiano.

No entanto, concentrações altas possibilitam o estabelecimento de condições onde microrganismos patogênicos aeróbios, tais como Clostridium botulinum possam crescer. Deve-se considerar também que a exposição de produtos frescos a concentrações de $\mathrm{O}_{2}$ e $\mathrm{CO}_{2}$, abaixo e acima do seu limite de tolerância, respectivamente pode aumentar a respiração anaeróbia e acelerar o desenvolvimento de odores desagradáveis, pelo aumento de etanol e acetaldeído (KADER, 1986). As combinações requeridas de temperatura, concentrações de $\mathrm{O} 2$ e $\mathrm{CO}_{2}$ variam com o tipo de produto vegetal, a variedade, a origem e a estação (SHEWFELT, 1986).

$\mathrm{O}$ armazenamento de produtos minimamente processados em condições adequadas é um ponto fundamental para o sucesso dessa tecnologia. Temperatura, umidade relativa e composição atmosférica no interior da embalagem são condições ambientais que podem ser manipuladas para diminuir a respiração. Depois da diminuição de temperatura dos produtos vegetais, considera-se que a embalagem 
em atmosfera modificada é o método mais eficaz para prolongar a vida útil de vegetais frescos e préprocessados (SCHLIMME; ROONEY, 1997).

A especificação de sistemas de embalagem com atmosfera modificada para frutas e hortaliças frescas, e minimamente processadas é muito complexa, pois diferentemente dos outros alimentos, estes produtos continuam respirando após a colheita e durante a sua comercialização (SARANTÓPOULOS, 1999).

A atmosfera modificada pode ser de forma passiva ou ativa. No caso da atmosfera passiva, o produto é acondicionado em embalagem e a atmosfera é modificada pela sua própria respiração. A atmosfera modificada ativa é criada injetando-se no espaço livre da embalagem uma mistura gasosa pré-determinada (YAM; LEE, 1995). Uma das vantagens da atmosfera modificada ativa é permitir a rápida estabilização da atmosfera desejada (ZAGORY; KADER, 1988), porém, a atmosfera final, dentro da embalagem, é semelhante nos dois processos.

Nos Estados Unidos há um acordo geral de que para o comércio a longas distâncias (entre estados), se requer 21 dias de vida útil entre o processamento e a compra final. Na comercialização regional, se necessita no mínimo 5 dias (SCHLIMNE; ROONEY, 1997). No Brasil, o que tem sido observado em supermercados, para a maior parte destes produtos, é a indicação de vida útil de 5 a 7 dias, embora a vida de prateleira comercialmente viável seja de pelo menos 15 dias (PAZINATO, 1999).

Segundo Wiley (1997), a ionização com radiações gama permite a desinfecção de produtos minimamente processados já embalados. A irradiação a doses baixas ( $1,0 \mathrm{kGy}$ ou menor) tem sido sugerida como uma técnica de processamento mínimo para prolongar a vida útil de algumas frutas e hortaliças (KADER, 1986). Vegetais cortados e embalados, irradiados com doses na ordem de 1,0 kGy exibiram atraso de vários dias na sua decomposição quando armazenados a $10^{\circ} \mathrm{C}$ (URBAIN, 1986).

Vieites, Evangelista e Silva (2000) trabalhando com melão minimamente processado e irradiado, verificaram que as doses de 0,1 e 0,2 kGy apresentaram resultados mais positivos no controle do amadurecimento, na prevenção de doenças e na maior durabilidade do produto.

Os custos de irradiação variam de US\$10 a 15 por tonelada para uma aplicação de baixa dose (para inibir o crescimento de brotos em batatas e cebolas, e aumentar a vida de prateleira de frutos) a US\$ 100 a 250 por tonelada para aplicação de alta dose(especiarias). Estes custos são competitivos com tratamentos alternativos. Em alguns casos, a irradiação pode ser consideravelmente menos dispendiosa (OELINCÉE, 1998). No Brasil esses custos estão bem parecidos segundo a própria EMBRARAD.

A irradiação, utilizada isoladamente ou em conjunto com outra técnicas de preservação, como o processamento mínimo, pode facilitar o alcance dos objetivos de segurança de alimentos e redução de perdas pós-colheita (TAPE, 1996; SANTIN, 2000).

A aplicação efetiva de tecnologia para o processamento mínimo de frutos e hortaliças depende, portanto, do conhecimento das características intrínsecas e microbiológicas que ocorrem nos mesmos.

O objetivo deste trabalho foi verificar o efeito de diferentes embalagens e da radiação gama no controle da contaminação microbiana da manga minimamente processada.

\section{Material e Métodos}

Após a colheita, mangas da cultivar Tommy Atkins foram transportados, em caixas de isopor de 16 litros refrigeradas com uma barra de gelo-x, a qual mantém a temperatura em torno de $16^{\circ} \mathrm{C}$, para o Laboratório de Frutas e Hortaliças do Departamento de Gestão e Tecnologia Agroindustrial pertencente à Faculdade de Ciências Agronômicas da UNESP, onde foram selecionadas de acordo com a sua maturação, com a cor da casca mais verde que vermelha, a consistência da polpa muito firme e sanidade, onde permaneceram a $10^{\circ} \mathrm{C}$ por $12 \mathrm{~h}$. A seguir os frutos 
foram processados (descascados e cortados em pedaços de 3 x $3 \mathrm{~cm}$, manualmente) e acondicionados em copos plásticos transparentes de $250 \mathrm{ml}$, contendo $200 \mathrm{~g}$ cada um, em sacos plásticos $25 \mathrm{~mm}$ a vácuo e em bandeja plástica rígida tereflatada tipo PET da Neoform.

Após o processamento mínimo, os copos, sacos plásticos e as bandejas com os frutos foram novamente acondicionados nas caixas de isopor com gelo e transportados até a EMBRARAD, localizada no município de Cotia-SP, onde foram submetidos aos tratamentos com diferentes doses de irradiação no irradiador do tipo "JS7500", no qual se utiliza como fonte o ${ }^{60}$ Cobalto e apresenta a taxa de $3,5 \mathrm{kGy} / \mathrm{h}$.

Os tratamentos a que foram submetidos os frutos minimamente processados foram: $\mathrm{T} 1$ - testemunha (0,0 kGy); T2 - 0,1 kGy; T3 - 0,2 kGy; T4 - 0,3 kGy; T5 - 0,4 kGy e T6 - 0,5 kGy. Após serem irradiados foram no mesmo dia transportados ao Laboratório de Frutas e Hortaliças em Botucatu-SP, e armazenados em câmara fria a $5^{\circ} \mathrm{C} \operatorname{com} 85 \%$ de UR.

Utilizou-se 25 embalagens para cada tratamento, na qual foram avaliadas a cada dois dias durante dez dias a contagem microbiológica. As amostras foram analisadas microbiologicamente, de acordo com a RDC n $n^{\circ} 12$ de 02 de janeiro de 2001. Segundo esta Resolução, o produto final não pode apresentar Salmonella, estafilococos coagulase positiva ou coliformes fecais e pode conter até 10 coliformes totais e até $10^{2}$ unidades formadoras de colônias de Bacillus cereus por grama de alimento (UFC/g).

A partir de cada produto foram avaliados quanto à evolução da contaminação de coliformes fecais, bolores e leveduras e microrganismos mesófilos aeróbios e anaeróbios facultativos, através da determinação do Número Mais Provável (NMP) de coliformes fecais e totais, essas análises serão realizadas de acordo com Kornacki e Johnson (2001), detecção da presença de Salmonella, segundo
Andrews et al. (2001), enumeração de estafilococos coagulase positiva (LANCETTE; BENNETT, 2001), enumeração de bactérias do grupo Bacillus cereus (BENNETT; BELAY, 2001), enumeração de Bolores e Leveduras (BEUCHAT; COUSIN, 2001) e enumeração de microrganismos mesófilos aeróbios ou anaeróbios facultativos (SWANSON et al., 2001).

O delineamento estatístico empregado foi o de blocos ao acaso, com 5 tratamentos e 5 repetições. Para comparação entre as médias utilizou-se o teste de Tukey a $5 \%$ de probabilidade, de acordo com Gomes (1987).

\section{Resultados e Discussão}

Todas as embalagens testadas nas doses de 0,4 e 0,5 kGy foram as mais eficientes no controle dos microrganismos mesófilos e psicotróficos (Tabela 1), concordando com Sarantópoulos (1999), no qual cita que a especificação de sistemas de embalagem com atmosfera modificada para frutas e hortaliças frescas e minimamente processadas é muito complexa, pois diferentemente dos outros alimentos, estes produtos continuam respirando após a colheita e durante a sua comercialização.

Os dados encontrados neste trabalho são semelhantes aos obtidos por Nguyen-The e Carlin (1994) em que relatam que em frutas e hortaliças minimamente processados a contagem de bactérias mesófilas variou de $10^{3}$ a $10^{9} \mathrm{UFCg}^{-1}$, dependendo do local de amostragem e do tempo decorrido até a análise; e com Fantuzzi (1999) que verificou em repolho minimamente processado a contagem iniciais de aeróbios mesófilos e psicotróficos foram de aproximadamente $10^{4} \mathrm{UFCg}^{-1}$ e não variaram significativamente no decorrer da estocagem enquanto o número inicial de anaeróbios de aproximadamente $10^{3}$ $\mathrm{UFCg}^{-1}$ não alterou em 20 dias de estocagem, em razão da manutenção de concentrações altas de $\mathrm{O}_{2}$ e $\mathrm{CO}_{2}$ no interior das embalagens. 
Tabela 1. Contagem de mesófilos e psicotróficos (U.F.C. - unidades formadoras de colônias) na manga minimamente processada, nos diferentes tratamentos, nos dias de armazenagem.

\begin{tabular}{|c|c|c|c|c|c|c|c|c|c|c|}
\hline \multirow[t]{2}{*}{ Tratamentos } & \multicolumn{4}{|c|}{ Mesófilos } & \multicolumn{6}{|c|}{ Psicotróficos } \\
\hline & 2 & 4 & 6 & 8 & 10 & 2 & 4 & 6 & 8 & 10 \\
\hline PET Test. & $>270$ & $2 \times 10^{2}$ & $7 \times 10^{3}$ & $10 \times 10^{6}$ & $13 \times 10^{9}$ & $<30$ & $>540$ & $2 \times 10^{4}$ & $2 \times 10^{5}$ & $12 \times 10^{6}$ \\
\hline PET 0,1 & $<30$ & $>540$ & $2 \times 10^{2}$ & $6 \times 10^{3}$ & $10 \times 10^{6}$ & $<30$ & $>540$ & $2 \times 10^{3}$ & $2 \times 10^{4}$ & $10 \times 10^{4}$ \\
\hline PET 0,2 & zero & $>270$ & $>670$ & $2 \times 10^{3}$ & $4 \times 10^{4}$ & zero & zero & $>540$ & $8 \times 10^{2}$ & $15 \times 10^{3}$ \\
\hline PET 0,3 & zero & $<50$ & $<320$ & $2 \times 10^{3}$ & $4 \times 10^{4}$ & zero & zero & $>540$ & $8 \times 10^{2}$ & $15 \times 10^{3}$ \\
\hline PET 0,4 & zero & $<50$ & $<320$ & $2 \times 10^{2}$ & $6 \times 10^{3}$ & zero & zero & $<200$ & $>540$ & $2 \times 10^{2}$ \\
\hline PET 0,5 & zero & $<50$ & $<320$ & $2 \times 10^{2}$ & $6 \times 10^{3}$ & zero & zero & $<200$ & $>540$ & $2 \times 10^{2}$ \\
\hline Copo Test. & $>270$ & $2 \times 10^{2}$ & $7 \times 10^{3}$ & $10 \times 10^{6}$ & $13 \times 10^{9}$ & $<30$ & $>540$ & $2 \times 10^{4}$ & $2 \times 10^{5}$ & $12 \times 10^{6}$ \\
\hline Copo 0,1 & $<30$ & $>540$ & $2 \times 10^{2}$ & $6 \times 10^{3}$ & $10 \times 10^{6}$ & $<30$ & $>540$ & $2 \times 10^{3}$ & $2 \times 10^{5}$ & $10 \times 10^{4}$ \\
\hline Copo 0,2 & zero & $>270$ & $>670$ & $2 \times 10^{3}$ & $4 \times 10^{4}$ & zero & zero & $>540$ & $8 \times 10^{2}$ & $15 \times 10^{3}$ \\
\hline Copo 0,3 & zero & $<50$ & $<320$ & $2 \times 10^{3}$ & $4 \times 10^{4}$ & zero & zero & $>540$ & $8 \times 10^{2}$ & $15 \times 10^{3}$ \\
\hline Copo 0,4 & zero & $<50$ & $<320$ & $2 \times 10^{2}$ & $6 \times 10^{3}$ & zero & zero & $<200$ & $>540$ & $2 \times 10^{2}$ \\
\hline Copo 0,5 & zero & $<50$ & $<320$ & $2 \times 10^{2}$ & $6 \times 10^{3}$ & zero & zero & $<200$ & $>540$ & $2 \times 10^{2}$ \\
\hline S.P. Test. & $>270$ & $2 \times 10^{2}$ & $7 \times 10^{3}$ & $10 \times 10^{6}$ & $13 \times 10^{9}$ & $<30$ & $>540$ & $25 \times 10^{4}$ & $20 \times 10^{5}$ & $30 \times 10^{6}$ \\
\hline S.P. 0,1 & $<30$ & $>540$ & $15 \times 10^{2}$ & $13 \times 10^{3}$ & $20 \times 10^{6}$ & $<30$ & $>540$ & $25 \times 10^{3}$ & $20 \times 10^{4}$ & $25 \times 10^{4}$ \\
\hline S.P. 0,2 & zero & $>270$ & $2 \times 10^{2}$ & $15 \times 10^{3}$ & $6 \times 10^{4}$ & zero & $>100$ & $2 \times 10^{2}$ & $25 \times 10^{2}$ & $2 \times 10^{4}$ \\
\hline S.P. 0,3 & zero & $<50$ & $>640$ & $15 \times 10^{3}$ & $6 \times 10^{4}$ & zero & $<30$ & $2 \times 10^{2}$ & $25 \times 10^{2}$ & $2 \times 10^{4}$ \\
\hline S.P. 0,4 & zero & $<50$ & $>640$ & $20 \times 10^{2}$ & $37 \times 10^{3}$ & zero & $<30$ & $>540$ & $2 \times 10^{2}$ & $25 \times 10^{2}$ \\
\hline S.P. 0,5 & zero & $<50$ & $>640$ & $20 \times 10^{2}$ & $37 \times 10^{3}$ & zero & $<30$ & $>540$ & $2 \times 10^{2}$ & $25 \times 10^{2}$ \\
\hline
\end{tabular}

Mesmo com as doses de 0,4 e 0,5 kGy, os frutos armazenados em saco plástico a vácuo apresentaram a maior contaminação microbiana tanto de mesófilos quanto de psicotróficos no período de armazenamento. Segundo Kader (1986) a exposição de produtos frescos a concentrações de $\mathrm{O}_{2}$ e $\mathrm{CO}_{2}$ respectivamente, abaixo e acima do seu limita de tolerância, pode aumentar a respiração anaeróbia e acelerar o desenvolvimento de odores desagradáveis pelo aumento de etanol e acetaldeido, fato este verificado neste trabalho em função do forte odor liberado dentro das embalagens quando abertas.

A ionização com radiações gama permite a desinfecção de produtos minimamente processados já embalados (WILEY, 1997). A irradiação a dose baixa (1,0 kGy ou menor) tem sido sugerida como uma técnica de processamento mínimo para prolongar a vida útil de frutas e hortaliças (KADER, 1986) fatos estes verificados neste trabalho, pois a irradiação principalmente nas doses de 0,4 e 0,5 kGy nos produtos embalados foram efetivas no controle da contaminação microbiana da manga minimamente processada.
Estes dados são concordantes com Urbain (1986), que verificou que vegetais cortados, embalados e irradiados com a dose de $1,0 \mathrm{kGy}$, exibiram atraso na sua decomposição quando armazenados a $10^{\circ} \mathrm{C}$.

Dado o baixo custo da irradiação de alimentos (OELINCÉE, 1998), o grande potencial da irradiação utilizada isoladamente ou em conjunto com outras tecnologias de preservação, como o processamento mínimo, no alcance da segurança alimentar e redução de perdas pós-colheita (TAPE, 1996; SANTIM, 2000) e o seu elevado controle no controle da contaminação microbiana, como verificado neste trabalho, a irradiação é uma técnica de grande potencial a ser utilizada em frutas minimamente processadas em especial o mamão.

Observa-se através da Tabela 2, os microrganismos encontrados nas amostras da manga minimamente processada nos diferentes tratamentos com irradiação, nas embalagens no período de armazenamento. Foram encontrados nos frutos do tratamento testemunha, os microrganismos do gênero Cladosporium sp, Curvularia sp, Epicoccum sp, Fusarium sp, Paecilomyces sp, Penicillium sp, 
Trichoderma sp e Rizoctonia sp. As doses de 0,1 a $0,3 \mathrm{kGy}$ controlaram apenas alguns microrganismos, porém não conseguiram controlar o Penicilluim sp, e a dose de $0,5 \mathrm{kGy}$ controlou todos os microrganismos. Estes dados estes semelhantes aos encontrados por Carvalho (2000) que cita que certos fungos produzem toxinas em alimentos que, quando ingeridos, causam sintomas tóxicos tanto ao homem como aos animais. Os gêneros de fungos de maior importância para humanos, com respeito a surtos de intoxicação, são :Aspergillus, Penicillium e Fusarium ssp. Esta grande quantidade de microrganismos encontrados deve-se, segundo Alvenainen (1996), à possível contaminação com bactérias, leveduras e mofos durante o descascamento, corte e fatiamento da manga e à maior superfície do produto vegetal exposta ao ar.

Tabela 2. Microrganismos encontrados nas amostras da manga minimamente processada nos diferentes tratamentos com irradiação nas embalagens no período de armazenamento.

\begin{tabular}{|c|c|c|c|c|c|c|}
\hline & \multicolumn{6}{|c|}{ Dose de irradiação (KGy) } \\
\hline Microrganismos & 0,0 & 0,1 & 0,2 & 0,3 & 0,4 & 0,5 \\
\hline Cladosporim $s p$ & $\mathrm{x}$ & $\mathrm{x}$ & $\mathrm{x}$ & $\mathrm{x}$ & & \\
\hline Curvularia sp & $\mathrm{x}$ & $\mathrm{x}$ & & & & \\
\hline Epicoccum sp & $\mathrm{x}$ & $\mathrm{x}$ & & & & \\
\hline Fusarium sp & $\mathrm{x}$ & $\mathrm{x}$ & $\mathrm{x}$ & & & \\
\hline Paecilomyces sp & $\mathrm{x}$ & & & & & \\
\hline Penicillium & $\mathrm{x}$ & $\mathrm{x}$ & $\mathrm{x}$ & $\mathrm{x}$ & $\mathrm{x}$ & \\
\hline Trichoderma $s p$ & $\mathrm{x}$ & & & & & \\
\hline Phomopsis sp & $\mathrm{x}$ & $\mathrm{x}$ & & $\mathrm{x}$ & & \\
\hline Rhizoctonia $s p$ & $\mathrm{x}$ & & $\mathrm{x}$ & $\mathrm{X}$ & $\mathrm{x}$ & \\
\hline
\end{tabular}

Pela Tabela 3, pode-se verificar que no presente trabalho não foram encontrados em nenhuma dos tratamentos, coliformes totais e coliformes fecais, estando de acordo a resolução $\mathrm{n}^{\circ} 12$ de janeiro de 2002 da Agência Nacional de Vigilância do Ministério da Saúde, o qual estabelece como padrão, o máximo de $5 \times 10^{2}$ NMP de coliformes fecais por grama de fruta (AGÊNCIA NACIONAL DE VIGILÂNCIA SANITÁRIA, 2002) e com Nguyen-The e Carlin (1994), que estudando a microbiologia de frutas e hortaliças minimamente processadas, verificaram que os coliformes em meio seletivo representaram uma pequena porção dos contaminantes bacterianos, enquanto os coliformes fecais não foram detectados na maioria das amostras estudadas.

Tabela 3. Contagem microbiológica encontrada nas amostras da manga minimamente processadas nos diferentes tratamentos com irradiação nas embalagens no período de armazenamento.

\begin{tabular}{lllllll}
\hline & \multicolumn{6}{c}{ Doses de irradiação (KGy) } \\
\hline Microrganismos & 0,0 & 0,1 & 0,2 & 0,3 & 0,4 & 0,5 \\
\hline Coliformes totais & zero & zero & zero & zero & zero & zero \\
Coliformes fecais & zero & zero & zero & zero & zero & zero \\
Bolores e Leveduras & $3 \times 10^{4}$ & $15 \times 10^{3}$ & $2 \times 10^{2}$ & $5 \times 10^{2}$ & $>200$ & zero
\end{tabular}

Observa-se uma pequena contaminação de bolores e leveduras na manga minimamente processada nos diferentes tratamentos, dados estes semelhantes aos encontrados por Nguyen-The e Carlin (1994), que relatam que em produtos minimamente processados as leveduras e fungos filamentosos, em geral são menos numerosos que as bactérias mesófilas. Resultados diferentes foram observados por Garg, Churey e Splittstoesser (1990), que trabalhando com hortaliças, verificaram que fungos filamentosos constituíam a minoria da população microbiana em repolho, alface, espinafre, cebola e couve-flor, sendo que os fungos predominantes eram as leveduras.

Porém, verificou-se, neste trabalho, grande eficiência da irradiação no controle da contaminação por bolores e leveduras, pois nos frutos dos tratamentos com a dose de $0,5 \mathrm{kGy}$, não se verificou contaminação nenhuma, enquanto que na testemunha a contagem foi de $3 \times 10^{4}$ e nos tratamentos com as doses de $0,1,0,2,0,3$ e $0,4 \mathrm{kGy}$, foram de $15 \times 10^{3}$, $2 \times 10^{2}, 5 \times 10^{2}$ e $>200$ respectivamente. Estes dados são semelhantes aos encontrados por Tape (1996) e Santim (2000), que citam que a irradiação isoladamente ou em conjunto com outras tecnologias de preservação, como o processamento mínimo, pode facilitar o alcance dos objetivos de segurança alimentar. 


\section{Conclusões}

Com base nos resultados obtidos, nas condições sensoriais em que o produto se encontrava e nas condições em que este experimento foi realizado, pode-se concluir que:

A irradiação mostrou-se um tratamento efetivo no controle microbiológico da manga minimamente processada.

As doses de 0,4 e 0,5 kGy foram as mais eficientes na sanitização da manga minimamente processadas.

A embalagem tipo PET foi a mais indicada para a manga minimamente processada.

\section{Referências}

ANDREWS, W.H.; FLOWERS, R. S.; SILLIKER, J.; BAILEY, J. S. Salmonella. In: DOWNES, F. P; ITO, K. (Ed.). Compendium of methods for the microbiological examination of foods. Washington: Apha, 2001. p.357-380.

AGÊNCIA NACIONAL DE VIGILÂNCIA SANITÁRIA. Resolução - RDC n.12, de janeiro de 2002. Disponível em: $<$ http://www.anvisa.gov.br/legis/resol/12 $01 \mathrm{rde} . \mathrm{htm}>$. Acesso em: 21 fev. 2002.

AHVENAINEN, R. New approaches in improving the shelf-life of minimally processed fruit and vegetables. Tends in Food Science \& Technology, Cambridge, v.7, n.6, p.179-187, 1996.

BENNETT, R. W.; BELAY, N. Bacillus cereus. In: DOWNES, F. P; ITO, K. (Ed.). Compendium of Methods for the Microbiological Examination of Foods. Washington: Apha, 2001.p.311-316.

BEUCHAT, L. R.; COUSIN, M. A. Yeasts and models. In: DOWNES, F. P; ITO, K. (Ed.). Compendium of Methods for the Microbiological Examination of Foods. Washington: Apha, 2001.p.209-215.

BRECHT, J. K. Physiology of lightly fruits and vegetables. HortScience, Alexandria, v.30, n.1, p.18-21, 1995.

BRETT, C., WALDRON, K. Physiology and biochemistry of plant cell wall. London: Hyman, 1990.

CARVALHO, A. V. Avaliação da qualidade de Kiwis cv. "Hayward" minimamente processados. 2000. Dissertação (Mestrado) - Universidade Federal de Lavras, Lavras. 2000.

CHERRY, J. P. Improving the safety of fresh produce with antimicrobial. Food Technology, Chicago, v.53, n.11, p.5459,1999 .
FANTUZZI, E. Atividade microbiana em repolho minimamente processado. 1999. Dissertação (Mestrado) - Universidade Federal de Viçosa, Viçosa, 1999.

GARG, N.; CHUREY, J. J.; SPLITTSTOESSER, D. F. Effect of processing conditions on the microflora of fresh vegetables. Journal of Food Protection, Des Moines. v.53, n.8, p.701-703, 1990.

GOMES, F. P. Curso de Estatística Experimental. 12.ed. Piracicaba: Nobel, 1987.

JERÔNIMO, E. M.; KANESIRO, M. A. B. Efeito da associação de armazenamento sob refrigeração e atmosfera modificada na qualidade de mangas: "Palmer". Revista Brasileira de Fruticultura, Cruz das Almas, v.22, n.2, p.237-242, 2000.

KADER, A. A. Biochemical and physiological basis for effects of controlled and modified atmospheres on fruits and vegetables. Food Technology, Chicago, n.5, p.99, 1986a.

KADER, A. A. Potential application of ionizing radiation in postharvest handling of fresh fruit and vegetables. Food Technology, Chicago, v.40, n.6, p.117-121, 1986b.

KORNACKI, J. L.; JOHNSON, J. L. Enterobacteriaceae, coliforms, and Escherichia coli as quality and safety indicators. In: DOWNES, F. P.; ITO, K. (Ed.). Compendium of methods for the microbiological examination of foods. Washington: Apha, 2001. p.69-80.

LANA, M. M.; FINGER, F. L. Atmosfera modificada e controlada: aplicação na conservação de produtos hortícolas. Brasília: EMBRAPA, 2000.

LANCETTE, G. A.; BENNETT, R. W. Staphylococcus aureus and Staphylococcal Enterotoxins. In: DOWNES, F. P; ITO, K. (Ed.). Compendium of methods for the microbiological examination of foods. Washington: Apha, 2001.p.387-403.

NGUYEN-THE, C.; CARLIN, F. The microbiology of minimally processed fresh fruits and vegetables. Critical Reviews in Food Science and Nutrition. Boca Raton, v.34, n.4, p.371-401, 1994.

O‘CONNOR-SHAW, R. E.; ROBERTS, R.; FORD, A. L.; NOTTINGHAM, S. M. Shelf life of processed honeydew, kiwifruit, papaya, pineapple and cantaloupe. Journal of Food Science, Chicago, v.59, n.6, p.1202-1215, 1994.

ODUMERO, J. A.; MITCHELL, S. J.; ALVES, D. M.; LYNCH, J. A.; YEE, A. J.; WANG, S. L.; STYLIADIS, S.; FARBER, J. M. Assessment of the microbial quality of ready-to-usevegetables for health-care food services. Journal of Food Protection, Des Moines, v.60, n.8, p.954960, 1997. 
OELINCÉE, H. Detection of food treated with ionizing radiation. Tends in Food Science \& Technology, Cambridge, v.37, p.73-82, 1998.

PAZINATO, B. C. Vegetais minimamente processados. Comunicado Técnico CATI, Campinas, n.142, p.1-4, 1999.

SAABOR, A. A importância dos minimamente processados. Frutifatos, Brasília, v.1, n.1, p.16-18, 1999.

SANTIN, M. La irradiación de los alimentos. Zaragoza: Acríbia, 2000.

SARANTÓPOULOS, C. I. G. L. Embalagens para vegetais minimamente processados: fresh-cut. Piracicaba: ESALQUSP, 1999.

SHEWFELT, R. L. Postharvest treatment for extending shelf-life of fruits and vegetables. Food Technology, Chicago, v.40, n.4, p.70-80, 1986.

SCHLIMME, D. V.; ROONEY, M. L. Envasado de frutas y hortaliças minimamente processadas. In: WILEY, Robert C. Frutas y hortalizas minimamente processadas y refrigeradas. Zaragoza: Acríbia, 1997. p.131-178.

SWANSON, K. M. J.; PETRAN, R. L.; HANLIM, J. H. título. In: DOWNES, F. P; ITO, K. (Ed.). Compendium of methods for the microbiological examination of foods. Washington: Apha, 2001. p.53-62.

TAPE, N. W. Protegendo nossas colheitas. Local: International Consultative Group on Food Irradiation, 1996.
URBAIN, W. M. Food irradiation. Orlando: Academic Press, 1986.

VANETTI, M. C. D. Controle microbiológico e higiene no processamento mínimo. In: ENCONTRO NACIONAL SOBRE PROCESSAMENTO MÍNIMO DE FRUTAS E HORTALIÇAS, 2., 2000, Viçosa. Anais.... Viçosa: UFV, 2000. p.44-51

VIEITES, R. L.; EVANGELISTA, R. M.; SILVA, A. P. Radiação gama no melão minimamente processado. In: CONGRESSO BRASILEIRO DE CIÊNCIA E TECNOLOGIA DE ALIMENTOS, 17., 2000, Fortaleza. Anais... Fortaleza: SBCTA, 2000.

ZAGORY, D.; KADER, A. A. Modified atmosphere packaging of fresh produce. Food Technology, Chicago, v.42, n.9, p.70-77, 1988.

WATADA, A. E.; ABE, K.; YAMUCHE, N. Physiological activies of partially processed fruits and vegetables. Food Technology, Chicago, v.23, p.23-47, 1990.

WILEY, R.C. Frutas y hortalizas minimamente processadas y refrigeradas. Zaragoza: Acríbia, 1997.

YAM, K. L.; LEE, D. S. Design of atmosphere packaging for fresh produce. In: ROONEY, M. L. Active food packaging. Glasgow: Chapman e Hall, 1995. p.573. 
